\title{
A Route to the Teaching of Polysemous Lexicon: Benefits from Cognitive Linguistics and Conceptual Metaphor Theory
}

Leonardo Veliz*

Deakin University, Australia

Corresponding Author: Leonardo Veliz, E-mail: leonardo.v@deakin.edu.au

\section{ARTICLE INFO}

\section{Article history}

Received: September 10, 2017

Accepted: November 17, 2017

Published: January 05, 2018

Volume: 7 Issue: 1

Advance access: December 2017

\author{
Conflicts of interest: None \\ Funding: None
}

\begin{abstract}
This paper discusses some implications and applications of the field of Cognitive linguistics (CL) to the teaching of English as a second, foreign or additional language (ESL, EFL or EAL). Some of the areas to which CL has immensely contributed are the teaching and learning of grammar, including modality and prepositions (e.g. Langacker, 1991; Langacker, 2008), the teaching and learning of lexis, especially metaphorically-used words and expressions (e.g. Boers, 2004; Deignan, Gabrys, \& Solska, 1997; Kalyuga \& Kalyuga, 2008; Kövecses, 1996), and the teaching and development of literacy skills, in particular the skills to better understand texts with metaphors embedded (e.g. Boers, 2000). A discussion of all these areas is certainly beyond the scope of this paper. The area to which some attention is drawn in this article is that of teaching metaphorical lexis, with a particular focus on the teaching of polysemous words. General suggestions and teaching recommendations are made in an attempt to bring this field closer to language practitioners.
\end{abstract}

Key words: Cognitive Linguistics, Metaphor, Language Teaching, Vocabulary, Polysemy

\section{AN OVERVIEW OF OUR CURRENT CONTEXT}

In their route to become proficient and successful language learners, several complex aspects of language must be deciphered, processed, learnt and used by those who have embarked upon the complex task of learning another language. Throughout the learning path, learners need to be exposed to "all aspects of language in use" as reflected in the implementation of language curricula and in the ways language is to be assessed (Christison \& Murray, 2014). These aspects of language in use comprise the English sound system, sentence structure, speech acts, the word system, amongst others (Christison \& Murray, 2014, p. 6) As far as vocabulary, or word system, is concerned, research has indicated that developing learners' lexicon is fundamental to the overall language ability. In reference to the Lexical Approach by Michael Lewis (1993), Moudraia (2001) stresses that the basis of language is lexis. This is affirmed by Boers (2013, p. 208) who indicates that "vocabulary size has been found to be a major contributor to proficiency". This, as a result, positions the learning of vocabulary in a central place within the teaching agenda.

Vocabulary, however, has not always been at the centre of language curricula. Far from being regarded as central to language learning, the teaching of vocabulary over the last five decades has been, on the whole, relegated to an inferior rank with respect to the teaching of grammar. Abrudan (2010) observes that vocabulary was, for many years, viewed as secondary to the overall purpose of language teaching, being the delivery of formal aspects of language, in particular grammar, the major preoccupation of language teachers and researchers. In the same way, Carter (1998) points out that the scant attention paid to the role of vocabulary in language learning has been, by and large, due to a growing concern for syntax, morphology and phonology which was particularly prevalent in the 1960s and 1970s. Such grammar-focused paradigm is said to be attributed to the influential and ground-breaking theories of syntax put forward by Chomsky in those days.

In recent years, the strong impetus on the teaching of grammar appears to be as latent as it was several decades ago. Boers and Lindstromberg (2008) point out that "theorists of FL pedagogy, particularly in English-speaking countries, have long tended to favour approaches that in one way or another discount the importance of teaching vocabulary..." (p.4). The emergence and proliferation of the Lexical approach (see Lewis, 1993) has generated an increasing interest in contextualizing the teaching of vocabulary by presenting lexis as combined with other items in meaningful chunks. This growing concern for vocabulary over grammar has manifested itself in a larger number of course books, teacher reference textbooks and teaching materials that have become available over the last decades. Despite this increasing emphasis on lexis over grammar, it seems that some language instructors do not seem to be 
well equipped to materialise the approach in a classroom context.

The effective instruction of vocabulary requires, first and foremost, that teachers are familiar with different aspects of what is involved in learning new words. Nation (2006) points out that learning a word "involves knowing several aspects covering the form, meaning, and use of the word". In dealing with these three features, teachers need to be conceptually and methodologically informed about how to systematically treat lexical items that are largely deemed as highly problematic and confusing to language learners. An example of this is what is known as 'polysemous' words. Aside from their ubiquity in written and spoken English, there has been consensus over the burdens they pose to both teachers and learners (Csábi, 2004; Makni, 2014). The complexity of this category of words lies primarily in the multiple related senses possessed by a single item, many of which are abstract metonymic or metaphorical extensions.

In traditional pedagogical contexts, polysemous words have been generally dealt with as arbitrary forms of language whose meaning extensions are peripheral to core meanings. Informed by more relatively recent theoretical paradigms, it has come to be acknowledged that polysemous vocabulary items are natural groups of senses (Lakoff \& Johnson, 1999a), and that metaphorical extensions have a basis on literal meanings (Makni, 2014). Despite the systematicities across the meaning extensions of a polyseme, the ineffective and unsuccessful pedagogical treatment of these items has been driven by misconceptions about the nature of meaning relations. Tyler and Evans (2004, as cited in Makni, 2014) points out that pedagogical attempts to teach polysemous words tend to be doomed to failure since meaning extensions are viewed as unrelated meanings that are accidentally coded by the same linguistic form. In an attempt to provide a broader pedagogical understanding of how polysemous words could be dealt with more effectively in classroom contexts, the present discussion taps into the various ways in which vocabulary is taught. In particular, it focuses upon a complex area of vocabulary teaching, that which relates to the teaching of metaphor-related vocabulary, with a particular focus on polyesemous words. To this end, the discussion draws on work within the field of CL, which sheds light on not only the motivations behind metaphor-related lexis but also on strategies for language teaching and learning.

\section{WHAT IS COGNITIVE LINGUISTICS?}

$\mathrm{CL}$ is a relatively new movement in the field of linguistics which has introduced various notions and approaches as to how language is represented in the mind through individuals' experiences in the world. CL refers to a particular branch traditionally associated with the work of George Lakoff, Ronald Langacker, Charles Fillmore and Gilles Fouconnier, all of whom made their contributions popular in the late 1980s. $\mathrm{CL}$ entails that it is not a single unified theory; rather, it is an interdisciplinary approach to language which subsumes a number of distinct theories with the purpose of explaining the relationship between language and other cognitive faculties and how these are mediated by our experiences in the world (Hart \& Lukes, 2007).

According to Evans and Green (2006), CL is a modern school of linguistic thought whose main purpose is to study the mind and socio-physical experience of human beings. In a similar vein, Ungerer and Schmidt (1996) have stated that $\mathrm{CL}$ is an approach to understanding language on the basis of our acquaintance, exposure and experiences of the world and, most importantly, on how we perceive and make mental representations of it.

The centrality of this experiential view of language is that meaning is viewed as embodied. That is, the nature of meaning is rooted in how our language and conceptual system are shaped by our bodily experiences with the world. One powerful way in which this interplay becomes clearly manifested is in how we talk about certain entities, generally abstract, in terms of other more concrete ones which are more familiar to what we have experienced in relation to the outside world. The basis of how our abstract concepts are structured in terms of what is more experientially concrete to us has been developed in what has come to be known as the Conceptual Metaphor Theory (CMT). This theory, embedded in the broader field of CL, sheds light on not only the metaphorical nature of thought and language but also on metaphor can be approached and eventually taught.

\section{COGNITIVE LINGUISTICS AND LANGUAGE TEACHING}

Although CL has already been around for over three decades, and yet regarded a relatively new approach to language, its implications for language teaching have only been investigated in recent years. Littlemore and Juchem-Grundmann (2010) point out that although CL can potentially contribute to our understanding of the second language learning process, 'it is a very new area and its implications are only just beginning to be explored' (p. 1). They go on to stress on the usefulness for language teaching instructors to develop familiarity with and knowledge of CL as this approach can provide them with tools to better understand how language teaching should take place and how languages should be taught.

On reviewing literature on CL that discusses implications and applications to the teaching of English as a second or foreign language, one finds reference to and evidence of how CL can contribute to different areas of pedagogy; the teaching of modal verbs (e.g. Tyler, Mueller, \& Ho, 2010), the teaching of grammar (e.g. Evans \& Green), the teaching of prepositions (e.g. Evans \& Tyler, 2008), the teaching of polysemous words (e.g. Makni, 2014), and the teaching of metaphor-related vocabulary in general (e.g. Boers, 2003; Kalyuga \& Kalyuga, 2008).

In regards to the teaching of prepositions, for instance, traditional explanations of the difference between 'in' and 'on' have typically focused on the former as implying the idea of 'inside' and the latter referring to 'the physical contact' between two surfaces. An example of this is such simple sentence as the book is on the desk, which clearly shows how two entities, the book and the surface of the desk, 
have come into contact. Explaining the semantic meaning of this preposition on the basis of how two entities touch each other is a feasible way of alerting language learners to the ways in which 'in' and 'on' differ from each other. However, the problem may arise when learners and teachers alike are faced with several other expressions containing the same preposition 'on' in contexts where it does not necessarily refer to actual contact between two entities. A clear case in point is that of prepositional verbs containing the preposition 'on'. Would the explanation of 'two entities coming into contact' be a sufficiently coherent way of explaining the semantic meaning of such verbs as 'count on', 'rely on', depend on', 'fall back on', 'base on', 'agree on' and several others? It seems that utilising the above-mentioned simple explanation of 'two surfaces coming into contact' would not be sufficiently effective for language learners to be able to understand the semantic meanings of these verbs. teachers are to use their skills, knowledge and immediate resources to find comprehensive and familiar ways to explain such verbs.

A central issue that has attracted the attention of many scholars, especially of those within the CL field, is to do with whether verbs such as those mentioned above, aside from carrying the same preposition, have any features in common. Evans and Green (2006) comment that a large number of prepositional verbs and phrasal verbs carry meaning which is systematically motivated by the ways in which we experience and interact with the world. This suggests that the meaning of these prepositional verbs is not to be treated as arbitrary, which is how meanings tend to be dealt with by language practitioners (Evans, 2003).

An explanation from CL to a possible relationship and systematicity between the different uses of the preposition 'on' in all different verbs would draw our attention to the ways in which we experience world phenomena. Our early experiences with reality provided us with the necessary knowledge of physics and gravity for us to come to understand that anyone who places, for instance, a cup of coffee on a table, it would fall to the ground if the table were removed. Such rudimentary, albeit fundamental, knowledge of gravity and physics has enabled young children to understand that the table does not only indicate a spatial scene (where the cup is) but also, and perhaps most importantly, that it serves the function of physical support (Tyler \& Evans, 2003); that is, the cup does not fall to the ground since the table is provide physical support so it remains where it is. This function of 'support' can also be extended and applied to different contexts of use of the above-mentioned prepositional verbs. Examples of these can be 'you can count on me', 'she relies on her parents', 'the actor fell back on her script', 'the assumption is based on theory and practice', 'politicians agreed on the implementation of a new policy', amongst others. In these cases, it becomes clear that the preposition 'on' is not referring to a spatial scenario but to non-physical support, thus revealing the ways meanings are extended from concrete to more abstract domains. In this way, one finds that all prepositional verbs in the above examples convey, by means of meaning extension, the idea of support in non-literal ways.
On lexical grounds, CL has considerably contributed to the teaching of polysemous words, phrasal verbs and idioms. These are areas with which language teachers have traditionally grappled due to the high levels of metaphoricity involved in them (Guo, 2007). It is likely that most language teachers, irrespective of how experienced they are, would agree on the complexity involved in teaching, for example, the so-called 'idioms'. Many of us have probably found ourselves on numerous occasions somewhat trapped in a 'no through' road and sometimes even confused about what constitutes an idiom, let alone the teaching of their semantic meaning. Perhaps, the greatest difficulty in teaching idioms is to do with their apparently arbitrary nature. Idioms, just like prepositions as discussed above, have been typically treated as rather unpredictable units whose meanings do not seem to relate to anything but pure arbitrariness (Cieslicka, 2006). Idioms, according to the CMT, share common underlying relationships which are linked to a particular conceptual metaphor. For instance, such linguistic realizations as 'she blew up at me', 'she just exploded', 'it was just adding fuel to the fire', largely investigated by Kovecses (1986), demonstrate that they are all linked to a common conceptual metaphor, that of 'anger is heat'. This suggests that part of the teacher's task is to find expressions that share common underlying features linked to a conceptual metaphor so they can be presented to learners in systematic rather than arbitrary ways.

As for the teaching of phrasal verbs, the most traditional way in which these are introduced in the majority of ESL textbooks is through thematic presentation. In other words, phrasal verbs are presented to learners in relation to the topic covered in the lesson. For instance, if a given unit is about the topic of 'Business' it is most likely that teachers will have to teach such phrases as set up (a business), close down, cut down (expenses), etc. If this is the way you as a teacher have typically introduced phrasal verbs in your lesson, I am confident that you run out of sensible explanations that account for the very nature of phrasal verbs and for the relationship between the phrasal verb (set up) and the topic (business). CL has demonstrated quite convincingly that many of what we call 'idioms' or 'idiomatic expressions' are far from being arbitrary. These expressions, which in most, if not all, cases carry a great deal of metaphoricity need to be pedagogically and methodologically treated in ways that differ from traditional pedagogies.

A possible route to understanding the metaphorical underpinnings of phrasal verbs and idioms and, in essence, of any metaphorically-intended expression, is through the lenses of the so-called CMT. The CMT is one of the dominant approaches within $\mathrm{CL}$, which has examined the underlying metaphorical relationships between language and thought. This theory has attracted a great deal of attention amongst researchers and, currently, applied linguists. Below is a description of how metaphor from the perspective of CMT differs from other views, namely philosophical and literary, and a discussion of key principles that underpin the very nature of CMT. 


\section{CONCEPTUAL METAPHOR THEORY}

Within the field of CL, one of the most prominent theories that has sparked interest in linguists, philosophers and psychologists is the CMT. The theory, which is originally associated with the seminal publication by Lakoff and Johnson (1980) 'Metaphors We Live By', is, as stated by Evans \& Green (2006), one of the first theoretical frameworks of cognitive semantics. Such publication impacted metaphor theory in such a way that it gave rise to the multidisciplinary CL enterprise, resulting in a cognitive revolution in the field. The central premise of the theory is that a conceptual metaphor (CM) is not simply a stylistic or ornamental device of language; rather, it is something that permeates the ways in which individuals reason and conceptualise the world. Thus, the theory of CM contends that not only is language metaphorical but also the nature of thought, and that how we think about the world is fundamentally metaphorical (Evans \& Green, 2006). What this suggests is that all the reasoning we do and language we express, which are naturally rooted in our minds, have emerged from our early experiences in the world, particularly from our sensorimotor and bodily interactions with the concrete reality.

Within the areas of poetry and literature, metaphor was for a long time conceived of as a figure of speech largely utilised as a decorative device in language. This narrow and predominantly ornamental view of metaphor was challenged by the CMT, which put forward the idea that, as already mentioned before, metaphor is not just a matter of language but of thought. This different and much more complex view of metaphor arises from three fundamental principles which are embedded in a larger framework of philosophical claims made by Lakoff and Johnson (1999, p.3). These three premises can be summarised thus:

(i) Thought is largely unconscious

(ii) Abstract concepts are fundamentally metaphorical

(iii) The mind is embodied.

The first claim addresses the idea that we cannot help thinking the way we do. While reason has been traditionally taken for more than two millennia as the essential and defining characteristics of human beings, we are not consciously aware of the way we reason. This would suggest that if the nature of our thinking and reasoning is primarily metaphorical, it is not up to the individual's choice to think and talk about the world in metaphorical terms. The practical and pedagogical implication of this principle may point in the direction of ensuring that teachers and students understand that metaphor is not a property of literary studies, a philosophical concern or a poetic device through which language is beautified, but a natural socio-cognitive tool that enables us to talk and think about the world around us. Such greater understanding of the nature of metaphor in language and thought must be developed, first and foremost, in English teacher education programs so that teachers are prepared to deal with metaphor more systematically. It is also important that such broader understanding of metaphor is also reflected in course curricula and syllabi so that it is pedagogically dealt with by teachers and teacher educators.

The second statement is based upon the idea that most of our nonphysical and abstract reality is conceptualized through physical reality. This is quite significant to the way in which thinking seems to be carried out. Firstly, it points to the necessity of relying on our most familiar and concrete world to understand, think and talk about abstract realities. A familiar lexical example would be the expression 'time is money', which shows a clear interplay between what people seem to be more familiar with, the concept of 'money', and a rather abstract entity, that of 'time', whose abstraction is revealed through the complex ways in which we typically grapple to define it. Perhaps less familiar examples, at least to some people, are those found in Biblical narratives. All of the parables told in the Bible were purposefully intended to communicate abstract and metaphorical messages by means of referring to the concrete realities with which people were familiar at the time. Examples of these were, and still are in the religious accounts, references to 'evil' in terms of 'wolves', 'power' in terms of 'fire', 'happiness' in terms of 'wine' along with the widely-known representations of 'purity', 'healing' and 'cleansing' in terms of 'water'.

Lastly, the third principle conveys the idea that concepts derive their meanings either directly or indirectly from sensorimotor experiences. This idea is rooted in the growing field within cognitive science known as embodied cognition or embodied mind thesis. This provides us with an examination of how interactions between our sensorimotor system and the environment plays an important role in the acquisition of knowledge (Siakaluk, Pexman, Aguilera, Owen, \& Sears, 2008). Allan (2001) stated that "...language is constrained and informed by the relations that human beings perceive in nature - particularly in relation to themselves...". The centrality of this principle to pedagogy relates, first of all, to the idea that language learning or, more broadly speaking, knowledge acquisition is essentially experiential. This emphasizes not only the role of our immediate interactions and experiences with the world in how we come to acquire knowledge, but also the experiential basis of metaphorical meanings. To teaching and learning, this principle implicates that teachers and learners should deepen their understandings of how (word) meanings are not arbitrary, but experientially motivated. This entails an enhanced awareness of how our bodily experiences with the world shape our mental and conceptual structures as well as our language use.

These three theoretical principles on which the notion of $\mathrm{CM}$ rests provide us with an overall understanding of what a $\mathrm{CM}$ is and how it is played out in language. Looking closely at what a CM is and how it is configured, it is important to know that it is comprised of two levels: a conceptual level and a linguistic one (Kövecses, 2010). The linguistic realisations of a conceptual metaphor refer to the either lexical or phrasal choices a speaker or writer has made to convey a particular message. The conceptual realisation, on the other hand, refers to the overall conceptual structure which underlies the linguistic level and, at the same time, frames the lexical or phrasal choices made at the linguistic level. For instance, if a speaker or writer uses linguistics expressions such as 'investing', 'commitment', 'compromises', 'deals', 'wasting', 'profits' etc. when talking about love, we could say that the conceptual structure which has made possible those 
linguistics expressions is one based on viewing or conceptualising love in terms of enterprise or business. The conceptual level is translated into the linguistic level in terms of viewing the lovers as though they were the two parties or companies involved in the business, their profits as achievements during the course o their relationship, investing as putting effort and time in making the business successful. Understanding that a metaphor involves a conceptual and a linguistic level, and that it also involves an interplay between an abstract domain and a concrete domain provides the backbone to the rest of the discussion which focuses primarily on the value of CL to the teaching of metaphor-related vocabulary.

\section{SUGGESTIONS FOR LANGUAGE TEACHING}

The type of lexis I wish to focus on in this section is one that generally conveys a great deal of metaphoricity - this is the case of polysemous words. There are several reasons for this choice. Firstly, the treatment of polysemous words in EFL contexts, as pointed out earlier, is typically by means of what Makni (2014) calls a 'translation-based vocabulary instruction method' (TBM). It is not unusual to come across translation-based practices in situations where teachers are faced with words with multiple meanings. Secondly, the problematic nature behind the teaching and learning of these words requires a systematic analysis of ways that facilitate their delivery and acquisition. In relation to the problems associated with polysemous words, Thornbury (2002) described them as a complete headache for students. Finally, the various meanings of a polysemous item and the relations between them are rarely treated as metaphorical extensions of their literal bases. I would doubt if extended meanings are, in practice, actually treated as metaphorical realizations originating from our early and primary bodily experiences with the world around us. In a nutshell, due to the pervasive nature of polysemy in English and the problems for teaching and learning, language teachers, especially in EFL contexts, need to deepen their understanding of alternatives ways to treat this ubiquitous lexical phenomenon to avoid traditional translation-based practices.

To assist in the teaching and learning of polysemous items I wish to make two interrelated teaching suggestions, both of which base their principles on raising learners' awareness of core literal meanings. The first suggestion focuses on developing awareness of how literal meanings extend into metaphorical extensions. To do this, teachers must have some understanding of certain CL principles, especially those relating to embodied cognition, as briefly discussed earlier. Raising learners' awareness of the literal core meaning would help them understand the motivations behind metaphorical extensions. Such awareness-raising process can be done by means of drawing students' attention to the prototypical meanings of the polyseme. For example, in teaching the polysemous item 'hold', teachers would have to signal such prototypes as 'hand' and 'control'. These can be written on the whiteboard, shown in a flashcard or slide, or explained with the assistance of body language. The same simple procedure can be utilized with any other polysemous item. Take for example the polyseme 'break'. Students can be asked to think of one or two prototypical words that best describe the core meaning of break. Some of the prototypes that can be written on the board are, for instance, 'separate', 'pause' or 'interruption'. Once teachers and students have one or two prototypes of the concept, teachers should provide examples of literal uses of the polysemes as in:

(i) 'The child broke the plate on the ground'

(ii) 'The girl fell and broke her arm'.

It is important to begin to raise students' awareness of how prototypical meanings become realised in the literal uses of the concept as shown in the example sentences. Then, the use of the word can be extended to more abstract domains to show students metaphorical meaning extensions. In this context, examples such as these may be given:

(i) The news broke my mother's heart

(ii) The student comes from a broken home.

Having provided students with some examples of metaphorical uses of the word, it is time to discuss with the students the features of the concrete domain (e.g. break an arm) that map onto the abstract/metaphorical domain (e.g. broken home). Do any of the prototypes of the polyseme 'break' (e.g. separation, pause, interruption) written on the board map onto the metaphorical uses? By raising awareness of our literal uses of words, students may come to understand how features of literal meanings are extended to metaphorical domains. In this way, teachers may use this simple procedure to show the systematicies of metaphorical meanings, and, thus, understand that literal and metaphorical senses are not to be understood as conflicting or contradictory.

Another approach I wish to suggest has its roots in a procedure that was designed by metaphor scholars to identify metaphorically-used words in naturally-occurring discourse. Although the procedure, called the Metaphor Identification Procedure (MIP), was not originally intended to be a teaching tool for raising metaphor awareness, its effectiveness has been documented in studies looking at the role of metaphor awareness in understanding of text (see Veliz, 2015).

The original version of the procedure is realised in four different steps where the third is sub-divided into three (see Semino, 2008, p. 23 for a full description of the steps). Since the MIP was devised to be used as a metaphor identification tool, not for metaphor-awareness raising purposes, the steps relevant to the present discussion are only two. These include:

1. For each lexical unit, determine if it has a more basic contemporary meaning in other contexts than the one in the given context. Basic meanings tend to be:

- More concrete; what they evoke is easier to imagine, see, hear, feel, smell, and taste.

- Related to bodily action.

- More precise (as opposed to vague).

- Historically older.

Basic meanings are not necessarily the most frequent meanings of the lexical unit.

2. If the lexical unit has a more basic-contemporary meaning in other contexts than the given context, decide whether the contextual meaning contrasts with the basic meaning but can be understood in comparison with it.

Despite the simplicity of these steps, they help teachers and learners focus on and attend to what Semino (2008) 
calls 'basic meanings'. Basic meanings are not only more concrete, literal, salient and more precise but connected with how individuals actually experience and interact with the world. This means that attending to the nature of basic meanings sheds light on how our physical and bodily relations with the world shape and frame both our conceptual system and our use of language. It is important to remember that, according to several metaphor scholars (Evans \& Green, 2006; Knowles \& Moon, 2006; Lakoff \& Johnson, $1980,1999 b)$, metaphor is experientially motivated. That is, the ways in which we have experienced and interacted with the world have an important role in how we not only talk about the world but in how we think about it. The implication of this for the teaching of metaphor-related words is that language teachers must rely upon their understanding of how language, especially metaphorical words, is rooted in our primary bodily and sensorimotor experiences with the world.

In trying to apply the above steps of the MIP, the language teacher must begin by compiling words often used metaphorically. While doing the compilation, you may realise that several of the words you have thought of are not traditionally considered metaphorical. Think, for instance, of the word 'close'. This is a word that comes up so regularly in our everyday conversations, and in language in general, that you would probably not consider metaphorical. What has happened? Metaphor scholars (e.g., Ungerer \& Schmidt, 1996) believe that words such as 'close', 'head', and others have become so coventionalised in language that their metaphoricity seems to have disappeared and are, therefore, better referred to as 'dead metaphors'. Nevertheless, when we look at the multiple ways in which the word 'close' can be used, i.e. the different domains of use, one can observe that 'close' does have a great deal of metaphorical load. Consider the following examples:

(i) My cousin's son lives close to the main campus of Charles University

(ii) A close friend of mine visited us last week.

The first step recommends looking at the basic (concrete) meaning of the word. Students would, for example, read and discuss the two sentences and decide which use of the word yields more salient, familiar and concrete meanings to them - which one is easier to imagine or see? It is likely that most answers would indicate that the first sentence evokes more familiarity and salience. The reason being is mainly due to the experiential basis of language as discussed earlier. In this context, it is important that teachers be able to, first of all, identify the different domains of use in the example sentences. In the first sentence, the use of 'close' alludes to the concrete domain of 'physical space' and 'proximity', while in the second sentence it refers to the abstract domain of 'affection'. The cross-mapping of features from the concrete domain to the abstract domain is central to understanding metaphorical extensions of polysemous words. Some of the critical questions that arise here relate to whether students and teachers themselves are aware of these intricacies of language, and whether these are taught in any way to learners.
The application of the second step of the procedure consists of comparing basic or prototypical meanings of the item with the contextual meaning in the sentence. If students were trying to understand the metaphoricity underlying the second sentence, they should be asked to conjure up familiar contexts and situations in which they would use the word 'close'. Then, the teacher would ask them to compare their uses and meanings of the word with that of the context of the sentence. This should enable teachers and students to develop an awareness of the interplay of literal and metaphorical meanings, which, in turn, should make the metaphor more visible and comprehensible to the learners.

In conclusion, despite the pedagogical simplicity of the suggestions described above, it is critical that teachers begin to adopt and implement teaching approaches that assist their learners in identifying and understanding the systematicities of metaphorical words. A possible path to a successful pedagogy may be the implementation of a metaphor-awareness raising approach. Whether it be by drawing learners' attention to the prototypes of polysemous words or by the application of the first two steps of the MIP, students and teachers alike must come to an understanding of how metaphor is not an arbitrary phenomenon, but a systematic way of thinking and speaking that is both embodied in our early physical experiences with the world and embedded in our socio-cultural contexts.

\section{CONCLUSION}

This paper set out to discuss some of the contributions and implications of CL for language teaching and learning of polysemous words. It has been discussed that CL has multiple applications to such areas as grammar and lexis providing us with a more comprehensive way of understanding the systematicities which underpin both lexical and grammatical relationships. By implementing a CL approach to teaching in our classrooms, our learners could be better afforded with practical orientations and explanations for what is traditionally regarded as arbitrary -phrasal verbs, idioms, prepositions, modal verbs, polysemous words, among others. Our learners would then come to understand that the apparently unrelated literal and metaphorical meanings of words have a common basis. Understanding the experiential basis of language should enable learners to comprehend that much of our language is metaphorical, and that those metaphorical linguistic realizations represent patterns of thought.

By way of conclusion, it is pertinent to ask how teachers are dealing with metaphor in the English classroom. Perhaps, we should start asking: are teachers dealing with metaphor at all? Are they prepared to deal with metaphor in a way that allows learners to see the underlying systematicities? Have teacher education programs provided teachers with the methodological and pedagogical tools to treat metaphor as a matter of language and thought, not as a poetic or literary device? It is time teachers and teacher educators started to consider realistic options to include the teaching of metaphor more seriously. 


\section{REFERENCES}

Abrudan, C. (2010). Vocabulary and language teaching Annals of the University of Oradea, 19(2), 170-173.

Boers, F. (2000). Enhancing metaphoric awareness in specialised reading. English for Specific Purposes, 19(2), 137-147.

Boers, F. (2004). Expanding learner's vocabulary through metaphor awareness: What expansion, what learners, what vocabulary? In M. Achard \& S. Niemeier (Eds.), Cognitive Linguistics, Second Language Acquisition, and Foreign Language Teaching. Berlin: Mouton De Gruyter.

Boers, F. (2013). Cognitive linguistic approaches to teaching vocabulary. Language Teaching, 46(2), 208-224.

Carter, R. (1998). Vocabulary: Applied Linguistics Perspectives London \& New York Routledge.

Christison, M., \& Murray, D. (2014). What English laguage teachers need to know: Designing curriculum. New York: Routledge.

Cieslicka, A. (2006). Literal Salience in on-line processing of idiomatic expressions by second language learners. Second Language Research, 22(2), 115-144.

Csábi, S. (2004). A cognitive linguistic view of polysemy in English and its implications for teaching. In M. A. S. Niemeier (Ed.), Cognitive Linguistics, Second Language Acquisition and Foreign Language Teaching. Berlin: Mouton De Gruyter.

Deignan, A., Gabrys, D., \& Solska, A. (1997). Teaching English metaphors using cross-linguistic awareness raising activities. ELT Journal, 51, 352-360.

Evans, V., \& Green, M. (2006). Cognitive Linguistics: An Introduction Edinburgh Edinburgh University Press.

Guo, S. (2007). Is idiom comprehension influenced by metaphor awareness of learners?A case study of Chinese EFL learners. The Linguistics Journal, 3(3), 148-166.

Hart, C., \& Lukes, D. (Eds.). (2007). Cognitive Linguistics in Critical Discourse Analysis: Application and Theory Newcastle: Cambridge Scholars Publishing.

Kalyuga, M., \& Kalyuga, S. (2008). Metaphor awareness in teaching vocabulary. Language Learning Journal, 36(2), 249-257.

Knowles, M., \& Moon, R. (2006). Introducing Metaphor. New York: Routledge.

Kövecses, Z. (2010). Metaphor: A practical introduction (2nd ed.). Oxford: Oxford University Press.

Kövecses, Z., \& Szabo, P. (1996). Idioms: A view from Cognitive Semantics Applied Linguistics, 17(3), 326-355.

Lakoff, G., \& Johnson, M. (1980). Metaphors We Live By. Chicago University of Chicago Press.
Lakoff, G., \& Johnson, M. (1999a). Philosophy in the Flesh: The Embodied Mind and the Challenge to Western Thought. New York: Basic Books.

Lakoff, G., \& Johnson, M. (1999b). Philosophy in the Flesh: The Embodied Mind and the Challenge to Western Thought New York Basic Books.

Langacker, R. (1991). Foudations of Cognitive Grammar (Vol. 2). Standford Standford University Press.

Langacker, R. (2008). Cognitive Grammar: A Basic Introduction New York Oxford University Press.

Lewis, M. (1993). The lexical approach. Hove: Language Teaching Publications.

Littlemore, J., \& Juchem-Grundmann, C. (2010). Introduction to the interplay between cognitive linguistics and second language learning and teaching. AILA Review, 23(1-6).

Makni, F. (2014). Applying of cognitive linguistics to teaching polysemous vocabulary. Arab World English Journal, 5(1), 4-20.

Moudraia, O. (2001). The lexical approach to second language teaching. The ERIC Clearinghouse on Languages and Linguistics Retrieved June 2013.

Nation, I. S. P. (2006). Second language vocabulary. In Encyclopaedia of Language and Linguistics (Vol. 13, pp. 448-454). Oxford: Elsevier.

Semino, E. (2008). Metaphor in discourse Cambridge Cambridge University Press.

Siakaluk, P., Pexman, P., Aguilera, L., Owen, W., \& Sears, C. (2008). Evidence for the activation of sensimotor information during visual word recognition. Cognition, 106(1), 433-443.

Thornbury, S. (2002). How to teach vocabulary. Malaysia: Pearson Longman.

Tyler, A., \& Evans, V. (2003). The semantics of English prepositions: Spatial scenes, embodied meaning and cognition Cambridge Cambridge University Press.

Tyler, A., \& Evans, V. (2004). The case of over. In M. Achard \& S. Niemeier (Eds.), Cognitive linguistics, second language acquisition, and foreign language teaching (pp. 257-280). Berline/New York: Mouton de Gruyter.

Tyler, A., Mueller, C., \& Ho, V. (2010). Applying cognitive linguistics to instructued L2 learning: The English modals. AILA Review, 23, 30-49.

Ungerer, F., \& Schmidt, H. (1996). An Introduction to Cognitive Linguistics. Edinburgh: Longman.

Veliz, L. (2015). Enhancing ESOL learners' understanding of text through conceptual metaphor awareness. Unpublished Doctoral thesis. Deakin University. Melbourne. 